by Irving S. Johnson

\title{
A COHERENT U.S. BIOTECHNOLOGY POLICY
}

M

ost technologically developed countries have a well defined science policy, in which biotechnology is targeted for support as a national goal. The United Kingdom, France, West Germany, the Soviet Union, and, even more vigorously, Japan have national efforts involving government support of industrial-academic collaborations, financial support of private companies, legislative support, and rapid modification of scientific guidelines.

In contrast, the United States' policy appears to be in some turmoil. The Environmental Protection Agency has not been given any specific authority in this area, but has loosely interpreted the Toxic Substances Control Act and the Federal Insecticide, Fungicide, and Rodenticide Act to encompass DNA as a potentially hazardous chemical. The Departments of Defense, Commerce, and State debate the extent of restrictions on exporting biotechnology to other countries. Lawsuits filed in U.S. courts challenge a host of biotechnology issues ranging from deliberate release of microorganisms, to patent questions (particularly those involving universities and industry), to the rights of patients to share in profits of biotechnology created from their body tissues. In all of these areas, industrial participation in formulating national policy has been largely restricted, if not nonexistent. Many initiatives need to be addressed in terms of a comprehensive national science policy in biotechnology: supporting basic research; targeting in areas like bioprocessing, plant molecular biology and biochemistry; improving intellectual property law; regulating technology transfer rather than products; modifying import-export regulations, to name a few.

The National Institutes of Health $(\mathrm{NIH})$ originally established guidelines for recombinant DNA research under the Recombinant DNA Advisory Committee (RAC). Both academia and industry have adhered to the guidelines and have sought RAC approval as necessary. This single scientific oversight system of review and recommendation is considered by nearly all to have functioned in an exemplary fashion. The gamut of controversial issues and experimental proposals has been brought forward, accepted for discussion, and acted upon in the light of current knowledge-all with dispatch. These issues include deliberate release to the environment and human gene therapy, and will probably include the issue of "convertibility" for military uses. Many of us feel that the United States' success in maintaining a fragile competitive edge in biotechnology-entirely without government subsidy of the fledgling industry-is at least partially due to the simplicity of the approach and adaptability of the RAC. This competitive edge is undoubtedly due to the U.S.'s long history of funding of basic research. Thus, with the exception of hybridoma technology, the major recent discoveries leading to modern biotechnology have been made in the United States. These include methods for manipulating, reading, cutting, and splicing DNA chains. Seen in this light, the disarray of U.S. policy seems surprising.

In the last half of this decade, the United States will clearly compete with coordinated efforts in biotechnology from most of the industrialized countries. The U.S. Office of Science and Technology Policy (OSTP) has published a Proposal for a Coordinaled Framework for Regulation of Biotechnology, (Federal Register, 49: 50856, Dec. 31, 1984). The Proposal recommends establishing separate rDNA Advisory Committees within the Food and Drug Administration (FDA), EPA, Department of Agriculture (USDA), $\mathrm{NIH}$, and National Science Foundation (NSF). The FDA, EPA, and USDA have provided position statements, included in the Proposal, but NIH and NSF provided none. It is lamentable that these two groups did not participate in formulating this policy. The statements from the FDA and USDA acknowledge that they have no need for additional authority for regulation and will deal with biotechnology on a case-by-case basis. There are inconsistencies in the FDA statement. The agency says on one hand that it intends to regulate products "based on a rational and scientific evaluation of products and not on $a$ priori assumptions about certain processes," yet it says that animal and food additive products must be subject to approval "even if the active substance is shown to be identical to that in approved products produced by conventional methods." In contrast, the USDA policy statement notes that agriculture and forestry products developed by biotechnology will not differ fundamentally from conventional products.

The OSTP proposal provides for a second or different review process for biotechnology products by establishing a Biotechnology Science Board (BSB). This creates a twotiered system in which submissions are made to the appropriate authority, which forwards them to BSB, which may send the proposal back with recommendations or send them on to yet another authority for further consideration. Products of biotechnology are not inherently different from "conventional" products. The national competitive interest would be better served if the BSB were to promote our ability to compete rather than inhibit it by a redundant, two-tiered regulatory process.

Finally, the public needs to be represented and reassured by a responsible, qualified group which encompasses scientific, ethical, governmental, environmental, and public interests. The RAC already contains these elements. The BSB could be structured to contain them as well. By proposing that biotechnology be regulated by a complex two-tiered process, the myth-that biotechnology's products are different and potentially dangerousis perpetuated and falsely substantiated. The public interest is best served by a single, broadly based oversight group, such as the RAC or its equivalent, rather than by a super-regulatory group, such as the BSB. These are considerations which need to be carefully considered in terms of fulfilling the expectations from this new technology, our ability to compete internationally, and the public perception of the science.

Irving S. Johnson, Ph.D., is vice president of research at Lilly Research Laboratories, Lilly Corporate Center, Indianapolis, IN 46285. These opinions are the author's own, and are not necessarily those of Bio/Technology. 